\title{
Thought Experiment: Marginal Cost versus John M. Clark's Workable Competition Pricing
}

\author{
Gerald Aranoff \\ Ariel University, Ariel, Israel \\ Email: garanoff@netvision.net.il
}

How to cite this paper: Aranoff, G. (2020). Thought Experiment: Marginal Cost versus John M. Clark's Workable Competition Pricing. Modern Economy, 11, 1742-1751. https://doi.org/10.4236/me.2020.1111119

Received: October 11, 2020

Accepted: November 14, 2020

Published: November 17, 2020

Copyright $\odot 2020$ by author(s) and Scientific Research Publishing Inc. This work is licensed under the Creative Commons Attribution International License (CC BY 4.0).

http://creativecommons.org/licenses/by/4.0/

\begin{abstract}
This article compares numerical results for an original model of an industry using marginal cost pricing versus workable competition pricing with fluctuating demand with two alternative technologies. The article is a thought experiment in economics, carried out only in the imagination. The article presents a detailed numerical model of a basic industry, cement manufacturing with large numbers of sellers, cement manufacturers, and large numbers of buyers, the construction industry, operating independently with full knowledge of supply and demand conditions. In the model cement plants have linear total cost functions with absolute capacity limits. The article considers two alternative technologies: 1) plant ${ }_{L}$ old plants with low fixed costs and high marginal costs and 2) plant $K_{K}$ new plants with high fixed costs and low marginal costs. This study argues in support of John M. Clark (18841963) workable competition theory in contrast to marginal cost competition theory. The study examines likely equilibrium conditions under two alternate pricing systems: a) short-run marginal cost pricing and b) John M. Clark's concept of workable competition. Workable competition raises prices above marginal costs in the off peak period and lowers prices in the peak periods. The study assumes frequency of off periods $6 / 7$ and frequency of peak periods $1 / 7$. The study claims, under the assumptions of the model, workable competition pricing add to consumer surplus over the cycle.
\end{abstract}

\section{Keywords}

Manufacturing, Business Cycle, Peak-Load Pricing, Cutthroat Competition, Workable Competition, Equilibrium, Cost Curves

\section{John M. Clark: Overhead Costs and the Business Cycle}

John M. Clark (1884-1963) attributed the main problems of the business cycle to the dominant role of fixed costs that are incurred irrespective of output rates. 
John M. Clark (1923) writes ${ }^{1}$ that overcapacity for the great majority of the time is normal and to be expected:

"What governs the supply of productive capacity in an industry?

...In the first place, owing to the forces already studied in connection with the business cycle, plant capacity is governed far more by the peak demand than by the minimum or the average. If this were not true, and if business did not build for the peak at the time of the upswing, one of the chief causes of business cycles would disappear. This very building for the peak, timed as it is, tends powerfully to increase the height of the peak itself.

...To sum up, it appears that there are strong forces at work which tend naturally to produce an oversupply of permanent capital, and there are decided indications that such as oversupply exists."

Fluctuations in manufacturing and construction are far more intense than fluctuations in demand for final goods and services. This is due to economic reasons that Clark (1923: pp. 389-390) explains well:

"The demand for means of production fluctuate more violently than that for finished consumers' goods, and also appears to fluctuate sooner, taking the lead in a way which would suggest that its changes are a cause, rather than an effect, of the changes in consumers' demand. In point of fact they are both effect and cause, as we shall see in a moment. Something similar is true of raw materials as compared to finished goods, while wholesale prices fluctuate more than retail... the physical need for new equipment shows a tendency to fluctuate more intensely than the demand for the finished product, because it depends, not upon the total volume of demand, but upon the rate of growth (or shrinkage): the amount added, for example, during the current year."

Clark is a business-cycle economist. Clark has insights today with the world in a general recession and with interest rates hovering over zero. Clark calls the down business cycle "the disease." Clark argues that farsighted and public-spirited managers must determine if society can meet peak-cycle demand, even though the peaks of the cycle are infrequent.

In my study on Clark and the U.S. cement industry (Aranoff, 1991), I propose a definition of industry under-capacity: "Industry under-capacity exists if persistently, over considerable periods, there are acutely raised prices, product shortages, costs and inconveniences of waiting lines and higher costs of substitutes at times of high level or peak demand." With my definition industry under-capacity can exist even in a depression with rampant idle capacity. Why? Because the next business upturn will be stopped for lack of capacity to meet peak-cycle demand.

Clark's view is that low depression prices make the business cycle worse. Low prices lead to a further shrinkage of manufacturing and construction activities. What then is there to do during a depression? Clark is generally against price cutting during economic downturns, calling it suicidal. Globalization makes ${ }^{1}$ John M. Clark, 1923, pages 437-439. 
countries similar to two local supermarket chains. In a depression it doesn't pay for one chain to offer free bread. The other chain would simply match it and both chains would be worse off. Clark calls this spoiling the market.

The Talmud discusses a depression in wine and olive oil in Palestine and linen in Babylon, the manufacturing industries at the time, the major sources of income for the people. The Talmud calls for crying out to God when prices are ruinously low:

"Our Rabbis taught: Public prayers are offered for goods [which have become dangerously cheap], even on the Sabbath. R. Johanan said: For instance linen garments in Babylon and wine and oil in Palestine. R. Joseph said: This [is only so] when [these have become so] cheap that ten are sold at [the price of] six (Baba Bathra 91a)."

\section{Research Questions}

Welfare economics theory claims that under certain conditions short-run marginal cost pricing under demand fluctuations maximizes consumer surplus. Consumer surplus is the theoretical maximum consumers are willing to pay above what they actually do pay for goods. Consumer surplus in economics is used as a measurement of social welfare. Consumer surplus can be defined as the area under the demand curve above the cost line. This study examines in a numerical model A, short-run marginal cost pricing versus $\mathrm{B}$, workable competition pricing with only plant $t_{L}$ technology and with only plant ${ }_{K}$ technology. The research questions include: What can we reasonably expect on the differences between prices and quantities in high demand times versus low demand times with plant ${ }_{L}$ and plant ${ }_{K}$ ? What can we reasonably expect on the differences in consumer surplus and in consumer satisfaction with plant ${ }_{L}$ and plant ${ }_{K}$ ?

John M. Clark was president of the American Economic Association in 1935. Clark supported economists arguing issues in the public knowing well the nature of political arguments. John M. Clark (1960) writes ${ }^{2}$

"Perhaps the most hopeful sign is the disposition of both to argue their case before the public. True, the arguments used on both sides suggest a rather cynically low estimate of the public intelligence, and a liberal use of red herrings; but this is characteristic of popular discussion in general. It is only more serious here in proportion as the issues are more serious."

A red herring is a fallacy argument that distracts from the original topic. The research questions here focus on the topic short-run marginal cost pricing sometimes called perfect competition versus Clark's workable competition.

\section{The Definition of the Model Its Terms and Assumptions}

This study models a hypothetical cement industry, product $Q$. The model assumes periods of a week. $q$ is the operating rate, tons of cement, produced in a ${ }^{2}$ John M. Clark, 1960, p. 121. 
week. $Q$ is a single homogeneous semi-perishable product, costly to store. Investors seeking to invest in manufacturing product $Q$ can choose between two hypothetical plants: 1) modern high FC Plant ${ }_{K}$ and 2) old low FC Plant $t_{L}$. Both plants have durable and specific assets and linear short-run total costs curves with absolute capacity limits. The plants differ in per-unit variable cost, $b$, per-unit fixed cost, $\beta$, and capacity per plant, $q . b$ is the constant per-unit variable operating cost. $\beta$ is the per-unit fixed capacity cost where the numerator is the constant fixed costs per week and the denominator is the maximum the plant can produce in a week. $n$ is the number of plants, a continuous variable. Fractional plants are permitted. In the model there are no long-run economies of scale for each plant.

In the model, investors can order any number of plants $s_{K}$ or plants $s_{L}$. Investors cannot choose a mixture of plant ${ }_{K}$ and plant ${ }_{L}$. The industry will be comprised of only plants ${ }_{K}$ or only plants $s_{L}$. In the model all parties know the industry supply and demand data.

\section{Theoretical Analysis Pricing System A: SRMC Pricing}

See Table 1 data for short-run marginal cost pricing. The left column of Table 1 shows data for cement industry using only technology $\mathrm{y}_{L}$. The right column of Table 1 shows data for cement industry using only technology ${ }_{k}$. See Figure 1 only

Table 1. SRMC pricing only $L$ only $K$.

\begin{tabular}{|c|c|c|c|}
\hline Let $w_{1}=$ & $6 / 7$ & & \\
\hline Let $w_{2}=$ & $1 / 7$ & & \\
\hline$T C_{L}=b_{L} q_{i}+\beta_{L} q_{L}$ & & $T C_{K}=b_{K} q_{i}+\beta_{K} q_{K}$ & \\
\hline$T C_{L}=31.2 q_{i}+4.8 \times 0.9$ & & $T C_{K}=24 q_{i}+12 \times 0.72$ & \\
\hline$V C_{L}=$ & $\$ 31.20$ per ton & $V C_{K}=$ & $\$ 24.00$ per ton \\
\hline$F C_{L}=$ & $\$ 4.32$ plant per cycle & $F C_{K}=$ & $\$ 8.64$ plant per cycle \\
\hline$q_{L}=$ & 0.90 tons per cycle & $q_{K}=$ & 0.72 tons per cycle \\
\hline Let $P_{A 1}=V C_{L}=$ & $\$ 31.20$ per ton & Let $P_{A 1}=V C_{K}=$ & $\$ 24.00$ per ton \\
\hline$Q_{1}=A_{1}$ & 36.92 tons & $Q_{1}=A_{1}$ & 48.00 tons \\
\hline Let $P_{A 2}=$ & & Let $P_{A 2}=$ & \\
\hline$V C_{L}+\beta_{L} / w_{2}=$ & $\$ 64.80$ per ton & $V C_{K}+\beta_{K} / w_{2}=$ & $\$ 108.00$ per ton \\
\hline Let $Q_{2}=A_{2}$ & 53.33 tons & Let $Q_{2}=A_{2}$ & 60.00 tons \\
\hline$n_{L}=Q_{2} / q_{L}$ & 59.26 plants & $n_{K}=Q_{2} / q_{K}$ & 83.33 plants \\
\hline$P_{1} Q_{1} w_{1}+P_{2} Q_{2} w_{2}=$ & $\$ 1481.14$ per cycle & $P_{1} Q_{1} w_{1}+P_{2} Q_{2} w_{2}=$ & \$1913.14 per cycle \\
\hline$V C_{L}\left(Q_{1} w_{1}+Q_{2} w_{2}\right)=$ & $\$ 1225.14$ per cycle & $V C_{K}\left(Q_{1} w_{1}+Q_{2} w_{2}\right)=$ & $\$ 1193.14$ per cycle \\
\hline$F C_{L} n_{L}=$ & $\$ 256.00$ per cycle & $F C_{K} n_{K}=$ & $\$ 720.00$ per cycle \\
\hline$E(\pi)=$ & $\$ 0.00$ per cycle & $E(\pi)=$ & $\$ 0.00$ per cycle \\
\hline$P_{A 2}-P_{A 1}=$ & $\$ 33.60$ & $P_{A 2}-P_{A 1}=$ & $\$ 84.00$ \\
\hline$Q_{A 2}-Q_{A 1}=$ & 16.41 tons & $Q_{A 2}-Q_{A 1}=$ & 12.00 tons \\
\hline
\end{tabular}




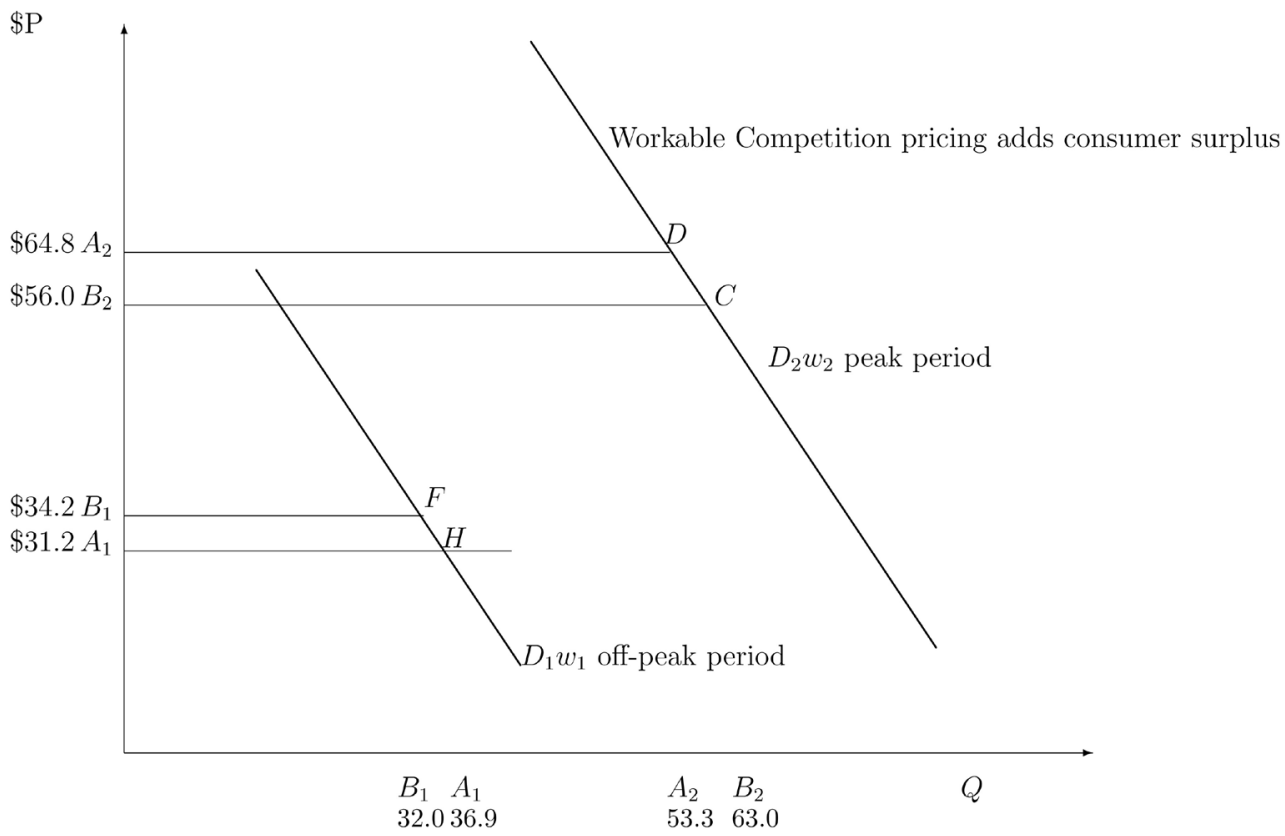

Figure 1. Only plant ${ }_{L} \mathrm{~A}$ v B MC v WC pricing.

plant $_{L}$ a graph of the data of the left columns of Table 1 and Table 2. See Figure 2 only plant $_{K}$ a graph of the data of the right column of Table 1 and Table 2.

The model assumes $w_{1}=6 / 7$ and $w_{2}=1 / 7$. The model assumes $T C_{L}=b_{L} q_{i}+\beta_{L} q_{L}$ and $T C_{K}=b_{K} q_{i}+\beta_{K} q_{K}$. The model assumes values: $b_{L}=31.2, \beta_{L}=4.8$, and $q_{L}=0.9$ to give $T C_{L}=31.2 q_{i}+4.8 \times 0.9$. The model assumes values $b_{K}=24, \beta_{K}=12$, and $q_{K}=0.72$ to give $T C_{K}=24 q_{i}+12 \times 0.72$.

The model assumes for only plant $P_{L} P_{A 1}=V C_{L}=\$ 31.2$. The model assumes for only plant $Q_{L}=A_{1}=36.92$ tons.

The model assumes for only plant $P_{K} \quad P_{A 1}=V C_{K}=\$ 24$. The model assumes for only plant $_{K} Q_{1}=A_{1}=48$ tons.

The model assumes for only plant $P_{A 2}=V C_{L}+\beta_{L} / w_{2}=\$ 64.8$. The model assumes for only plant ${ }_{L} Q_{2}=A_{2}=53.33$ tons.

The model assumes for only plant ${ }_{K} P_{\mathrm{A} 2}=V C_{K}+\beta_{K} / w_{2}=\$ 108.00$. The model assumes for only plant ${ }_{K} Q_{2}=A_{2}=60.00$ tons.

The number of plants for only plant $n_{L} n_{L}=Q_{2} / q_{L}=59.26$ plants $_{L}$.

The number of plants for only plant $n_{K} n_{K}=Q_{2} / q_{K}=83.33$ plants $_{K}$.

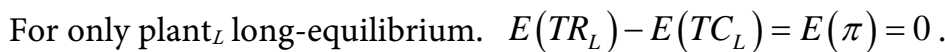

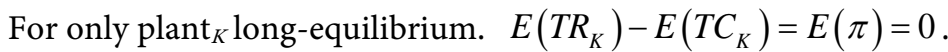

For only plant $P_{A 2}-P_{A 1}=\$ 33.60$. For only plant $P_{K} P_{A 2}-P_{A 1}=\$ 84.00$.

For only plant $Q_{A 2}-Q_{A 1}=16.41$ tons. For only plant ${ }_{K} Q_{A 2}-Q_{A 1}=12.00$ tons.

As can be seen the high FC plant, plant $K_{K}$, under SRMC pricing requires wider price differences between $P_{2}$ and $P_{1}$ and narrower output rates differences between $Q_{2}$ and $Q_{1}$. 


\section{Theoretical Analysis Pricing System B: Workable Competition Pricing}

See Table 2 data for John M. Clark's workable competition cost pricing. The left column of Table 2 shows data for cement industry using only technology $y_{L}$. The right column of Table 2 shows data for cement industry using only technology ${ }_{K}$. See Figure 1 only plant ${ }_{L}$ a graph of the data of the left columns of Table 1 and Table 2. See Figure 2 only plant $_{K}$ a graph of the data of the right column of $\mathrm{Ta}$ ble 1 and Table 2.

The model assumes to raise prices above SRMC pricing in off-peaks and to lower prices below SRMC pricing in peak periods. The model assume downward sloping demand schedules so that a rise in prices leads to less quantities demanded and a reduction in prices leads to more quantities demanded. A reasonable assumption is that off-peak demand is relatively inelastic so that a rise in prices would lead to higher revenues for sellers though they are selling fewer units.

The thought experiment of the hypothetical cement industry starts with long-run equilibrium under SRMC pricing as shown in Table 1. The thought experiment for workable competition raises prices in low demand times so firms have a positive $C M$, contribution margin, $P-V C=C M$. In pure SRMC pricing in low demand periods prices exactly equal $V C$. In SRMC pricing firms have losses in low demand times equal to their fixed costs in low demand times. In SRMC

Table 2 . WC pricing only $L$ only $K$.

\begin{tabular}{|c|c|c|c|}
\hline Let $w_{1}=$ & $6 / 7$ & & \\
\hline Let $w_{2}=$ & $1 / 7$ & & \\
\hline$T C_{L}=b_{L} q_{i}+\beta_{L} q_{L}$ & & $T C_{K}=b_{K} q_{i}+\beta_{K} q_{K}$ & \\
\hline$T C_{L}=31.2 q_{i}+4.8 \times 0.9$ & & $T C_{K}=24 q_{i}+12 \times 0.72$ & \\
\hline$V C_{L}=$ & $\$ 31.20$ per ton & $V C_{K}=$ & $\$ 24.00$ per ton \\
\hline$F C_{L}=$ & $\$ 4.32$ plant per cycle & $F C_{K}=$ & $\$ 8.64$ plant per cycle \\
\hline$q_{L}=$ & 0.90 tons per cycle & $q_{K}=$ & 0.72 tons per cycle \\
\hline Let $P_{B 1}=V C_{L}+3.00=$ & $\$ 34.20$ per ton & Let $P_{B 1}=V C_{K}+2.00=$ & $\$ 26.00$ per ton \\
\hline$Q_{1}=B_{1}$ & 32.00 tons & $Q_{1}=B_{1}$ & 46.00 tons \\
\hline Let $P_{B 2}=$ & $\$ 56.00$ per ton & Let $P_{B 2}=$ & $\$ 100.00$ per ton \\
\hline Let $Q_{2}=B_{2}$ & 63.00 tons & Let $Q_{2}=B_{2}$ & 66.00 tons \\
\hline$n_{L}=Q_{2} / q_{L}$ & 70.00 plants & $n_{K}=Q_{2} / q_{K}$ & 91.67 plants \\
\hline$P_{1} Q_{1} w_{1}+P_{2} Q_{2} w_{2}=$ & $\$ 1442.06$ per cycle & $P_{1} Q_{1} w_{1}+P_{2} Q_{2} w_{2}=$ & $\$ 1968.00$ per cycle \\
\hline$V C_{L}\left(Q_{1} w_{1}+Q_{2} w_{2}\right)=$ & $\$ 1136.57$ per cycle & $V C_{K}\left(Q_{1} w_{1}+Q_{2} w_{2}\right)=$ & $\$ 1172.57$ per cycle \\
\hline$F C_{L} n_{L}=$ & $\$ 302.40$ per cycle & $F C_{K} n_{K}=$ & $\$ 792.00$ per cycle \\
\hline$E(\pi)=$ & $\$ 3.09$ per cycle & $E(\pi)=$ & $\$ 3.43$ per cycle \\
\hline$P_{B 2}-P_{B 1}=$ & $\$ 21.80$ per ton & $P_{B 2}-P_{B 1}=$ & $\$ 74.00$ per ton \\
\hline$Q_{B 2}-Q_{B 1}=$ & 31.00 tons & $Q_{B 2}-Q_{B 1}=$ & 20.00 tons \\
\hline
\end{tabular}




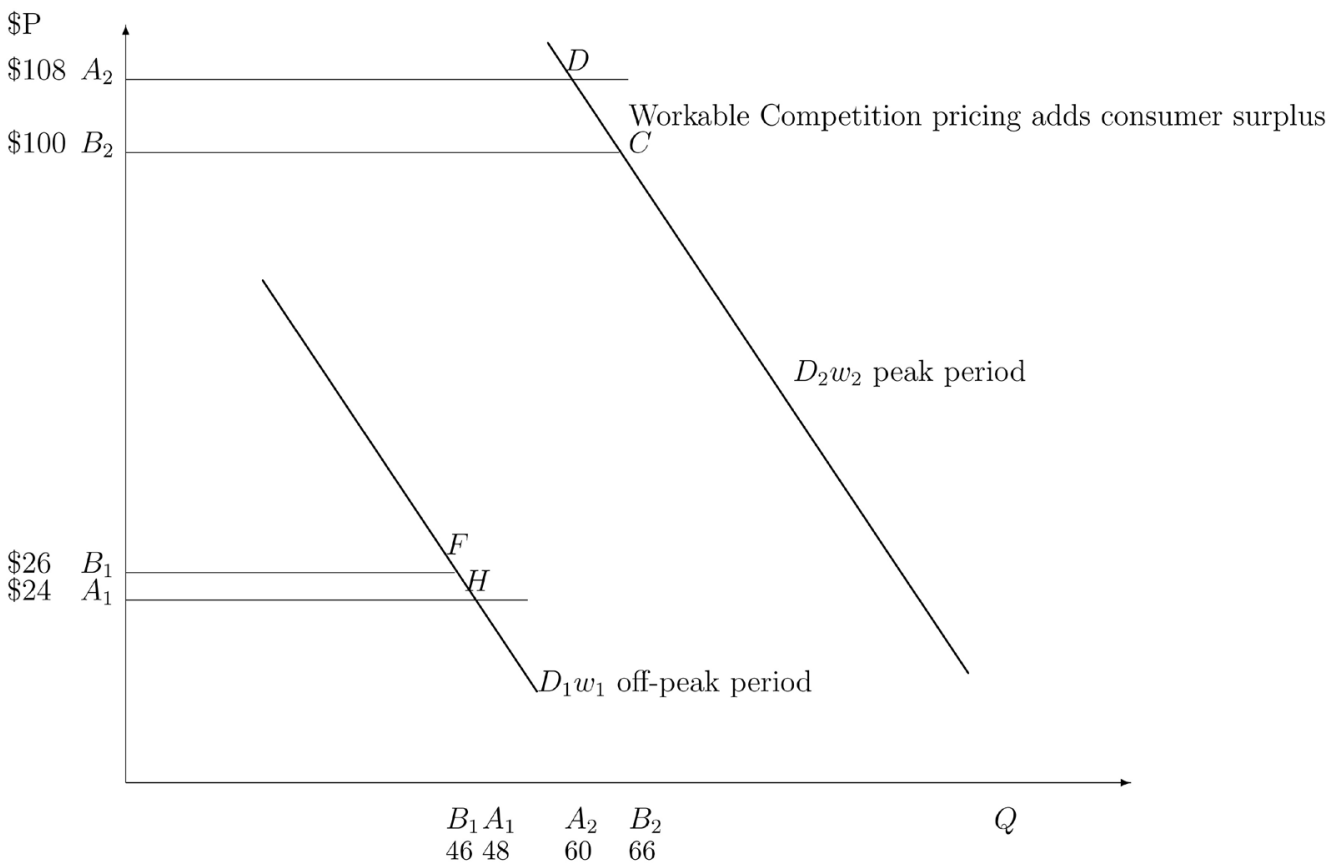

Figure 2. Only plant ${ }_{K} \mathrm{~A} v \mathrm{~B}$ MC v WC pricing.

pricing, for long run equilibrium to emerge over the cycle, prices are very high in high demand periods.

The model assumes in workable competition pricing firms will expand capacity more over the cycle. In high demand times prices would be lower with workable competition pricing than would be under SRMC pricing. Table 2 shows a reasonable long-run equilibrium arrangement under workable competition pricing. I use round numbers and rough estimates in Table 2 for workable competition to get approximate zero expected profits over the cycle. In Table 1 for SRMC pricing I use precise numbers to get exactly zero long-run equilibrium.

The model assumes $w_{1}=6 / 7$ and $w_{2}=1 / 7$. The model assumes $T C_{L}=b_{L} q_{i}+\beta_{L} q_{L}$ and $T C_{K}=b_{K} q_{i}+\beta_{K} q_{K}$. The model assumes values: $b_{L}=31.2, \beta_{L}=4.8$, and $q_{L}=0.9$ to give $T C_{L}=31.2 q_{i}+4.8 \times 0.9$. The model assumes values $b_{K}=24, \beta_{K}=12$, and $q_{K}=0.72$ to give $T C_{K}=24 q_{i}+12 \times 0.72$.

The model assumes for only plant ${ }_{L} P_{B 1}=V C_{L}+3.00=\$ 34.20$. The model assumes for only plant $Q_{L}=B_{1}=32$ tons.

The model assumes for only plant ${ }_{K} P_{B 1}=V C_{K}+2=\$ 26$. The model assumes for only plant ${ }_{K} Q_{1}=B_{1}=46$ tons.

The model assumes for only plant ${ }_{L} P_{B 2}=\$ 56.00$. The model assumes for only plant $_{L} Q_{2}=B_{2}=63.00$ tons.

The model assumes for only plant ${ }_{K} P_{B 2}=\$ 100.00$. The model assumes for only plant $_{K} Q_{2}=B_{2}=66.00$ tons.

The number of plants for only plant ${ }_{L} n_{L}=Q_{2} / q_{L}=70.00$ plants $_{L}$.

The number of plants for only plant ${ }_{K} n_{K}=Q_{2} / q_{K}=91.67$ plants $_{K}$. 


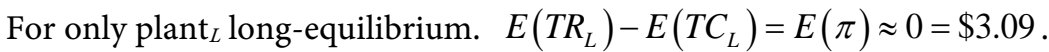

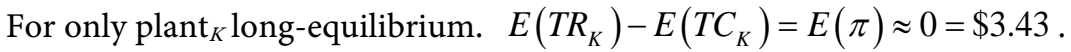

For only plant $T_{L} P_{B 2}-P_{B 1}=\$ 21.80$. For only plant ${ }_{K} P_{B 2}-P_{B 1}=\$ 74.00$.

For only plant ${ }_{L} Q_{B 2}-Q_{B 1}=31.00$ tons. For only plant $K_{K} Q_{B 2}-Q_{B 1}=20.00$ tons.

As can be seen the high FC plant, plant ${ }_{K}$ under workable competition pricing requires wider price differences between $P_{2}$ and $P_{1}$ and narrower output rates differences between $Q_{2}$ and $Q_{1}$.

With workable competition pricing in off-peak periods, market price is above VC. Firms have to restrain themselves from producing more than customers will buy at the market price. I assume firms produce to meet the demand schedules in the off-peak, no more and no less. In low demand times with only plants $s_{L}$ I assume $P_{B 1}=31.2+3.00=34.20 \$$ per ton and $Q_{B 1}=32$ tons based on a rough estimate of my demand curves. In low demand times with only plants ${ }_{K} \mathrm{I}$ assume $P_{B 1}=24+2.00=26 \$$ per ton and $Q_{B 1}=46$ tons based on a rough estimate of my demand curves. Surely helping firms in low demand times will lead to more plant investment to meet high demand, under long-run equilibrium. See only plants $s_{L}$ Table 3 and Figure 1 . See only plants ${ }_{K}$ Table 4 and Figure 2.

\section{Consumer Surplus Comparisons}

Consumer surplus is the area under the demand curve above the price line. Long-run equilibrium requires expected profits over the cycle $=0$. We can make a welfare judgment on which pricing system is better by seeing which pricing system likely yields more consumer surplus. I proved mathematically that a rigid pricing system over demand fluctuations that gives same expected revenues and same expected outputs is superior to a varying pricing (see Aranoff, 2011). My results are not dependant at all on the frequencies of the periods. Often business downturns are long and business upturns short. Often what end a business upturn are product shortages during peak demand times. I argue we should keep focus on adequate capacity to meet peak demand.

I claim here that workable competition pricing adds to consumer surplus whether only plant ${ }_{L}$ or only plant ${ }_{K}$ in comparison to short-run marginal cost

Table 3. Consumer surplus comparison only plant . $_{\text {. }}$

\begin{tabular}{ccc}
\hline Pricing rule & Equilibrioum points & Frequencies \\
\hline A: SRMC pricing & $(\mathrm{H}, \mathrm{D})(36.9, \$ 31.2),(53.3, \$ 64.8)$ & $w_{1}=6 / 7, w_{2}=1 / 7$ \\
B: WC pricing & $(\mathrm{F}, \mathrm{C})(32.0, \$ 34.2),(63.0, \$ 56.0)$ & $w_{1}=6 / 7, w_{2}=1 / 7$ \\
\hline
\end{tabular}

Table 4. Consumer surplus comparison only plant $K_{\text {. }}$

\begin{tabular}{ccc}
\hline Pricing rule & Equilibrioum points & Frequencies \\
\hline A: SRMC pricing & $($ H, D $)(48.0, \$ 24.0),(60.0, \$ 108.0)$ & $w_{1}=6 / 7, w_{2}=1 / 7$ \\
B: WC pricing & $($ F, C) $(46.0, \$ 26.0),(66.0, \$ 100.0)$ & $w_{1}=6 / 7, w_{2}=1 / 7$ \\
\hline
\end{tabular}


pricing. The thought experiment here demonstrates this with reasonable demand and cost numbers. For completely inelastic demand schedules short-run marginal costing and workable competition pricing give identical consumer surplus. More elastic the demand schedule in high demand leads to more consumer surplus under workable competition.

\section{Conclusions}

We present a theoretical model of manufacturing cement with two technologies, plant $_{L}$ and plant $_{K}$. We compare two pricing policies for each technology short-run marginal cost pricing versus workable competition over the business cycle. We show in our model a gain in expected consumer surplus with workable competition pricing. We give a detailed numerical example with graphs for each pricing system. The main result is that workable competition pricing over the business cycle increases the amplitude of $\mathrm{Q}$ outputs over the cycle and increases consumer surplus for both technologies under certain conditions. The positive effects of workable competition pricing seem more pronounced with plant ${ }_{L}$.

Much of our work is based on John M. Clark. He argued against SRMC pricing in industries facing cyclical demand fluctuations. Clark (1961: pp. 121-122) wrote that with SRMC pricing in cyclical industries firms would be operating at a loss for the great majority of the time, with vain hopes of exploiting the infrequent peak times:

"It is decidedly doubtful whether it would be economically feasible to make profits enough in such periods to offset the losses incurred in normal and subnormal periods. And if it were economically feasible, there might be other serious obstacles and drawbacks in the way of exploiting the profitable periods by raising prices as graspingly as would be necessary to balance accounts."

Clark's last paragraph in his 1961 book (Clark, 1961), applies today:

"Meanwhile it remains true that the imperfectly competitive mixed economy we have is better than the impossible abstraction of perfect competition... The system has serious shortcomings, but there is room to hope that our performance in these respects may be substantially improved, if all groups concerned attack the problems with a realization of their importance and with the necessary understanding and good will."

\section{Conflicts of Interest}

The author declares no conflicts of interest regarding the publication of this paper.

\section{References}

Aranoff, G. (1991). John M. Clark's Concept of Too Strong Competition and a Possible Case: The U.S. Cement Industry. Eastern Economic Journal, 17, 45-60.

Aranoff, G. (2011). Competitive Manufacturing with Fluctuating Demand and Diverse 
Technology: Mathematical Proofs and Illuminations on Industry Output-Flexibility. Economic Modelling, 28, 1441-1450.

https://doi.org/10.1016/j.econmod.2011.02.016

Clark, J. M. (1923). Studies in the Economics of Overhead Costs. Chicago, IL: The University of Chicago Press.

Clark, J. M. (1960). Alternative to Serfdom. New York: Vintage Books.

Clark, J. M. (1961). Competition as a Dynamic Process. Washington DC: The Brookings Institution. 